\title{
College Enquiry Chat-Bot System
}

\author{
Harshala Gawade \\ Computer Department \\ Saraswati College of Engg Kharghar, India \\ Vedika Patil \\ Computer Department \\ Saraswati College of Engg Kharghar, India
}

\author{
Prachi Vishe \\ Computer Department \\ Saraswati College of Engg Kharghar, India \\ Sonali Kolpe \\ Computer Department \\ Saraswati College of Engg Kharghar, India
}

\begin{abstract}
Nowadays, many people are using smartphone with many new applications i.e. technology is growing day by day. Today Artificial Intelligence is playing a major role in a variety of fields ranging from industries in product manufacturing, to customer care in public relations. As there are many online Artificial Intelligence (AI) systems or chat bots which are in existence that help people solve their problems. So, we are going to implement a virtual assistant based on AI that can solve any college related query. This will work as a College Oriented Intelligence machine. This virtual machine will respond the queries of students on college related issues. A chat bot has information stored in its database to identify the sentences and making a decision itself as response to answer a given question. The college enquiry chat bot will be built using algorithm that analyses queries and understand user's message.
\end{abstract}

Keywords- Artificial Intelligence, Database, Intelligence Machine.

\section{INTRODUCTION}

A chatbot is a software application used to conduct an online chat conversation via text or text-to-speech, in lieu of providing direct contact with a live human agent. Designed to convincingly simulate the way a human would behave as a conversational partner [14]. Bots can be created by using language like Artificial Intelligence Mark-up Language(AIML), a language based on XML that allow developer's write rules for the bot to follow. Another drawback is writing rules for different scenarios is very time consuming and it is impossible to write rules for every possible scenario. So these bots can handle simple queries but fail to manage complex queries is stated in paper [7]. In paper [2] the chat-bot system is been proposed and designed using chat fuel platform and integrated in Facebook page. The chatbot has been designed to provide students feel like talking to the staff from college and their queries are addressed through the conversational text. Responses can be provided to the user in text format, pictures and with many more features provided by the chat fuel. The setup AI feature makes the bot smart and answers the queries of user [2].

The purpose of developing this project is based on an intellectual chat-bot system which will deal with the academic activities like admission enquiry, fees structure, scholarship details, time-table of every department, details of the documents required to attach etc. With this chat-bot system it will be easy for the student to directly clear their queries in lesser time.

\section{LITERATURE SURVEY}

A literature survey is a comprehensive summary of previous research on a topic. The literature review surveys scholarly articles, books, and other sources relevant to a particular area of research. It should give a theoretical base for the research and help you (the author) determine the nature of your research. [14]

Prof. Ram Manoj Sharma [2] proposed a college enquiry chatbot system which has been built by using Artificial Intelligence algorithms. The bot analyses user's query and understands user messages. The system has modules like Online chatbot, Online Noticeboards etc[2].

P.Nikhila, G.Jyothi, K.Mounika, Mr. C Kishor Kumar Reddy and Dr. B V Ramana Murthy [3], they have designed using AIML (Artificial Intelligence Mark-up Language) to make response to queries. AIML is employed to make or customize alicebot that could be a chat-bot application supported ALICE free code [3].

Harsh Pawar, Pranav Prabhu, Ajay Yadav, Vincent Mendonca, Joyce Lemos [6], a chatbot is designed by them using knowledge in database. The proposed system has Online Enquiry and Online Chatbot System. The development is done using various programming languages by creating a user friendly graphical interface to send and receive response. The main purpose is it uses SQL (Structured Query Language) for pattern matching which is been stored in program [6].

Nitesh Thakur, Akshay Hiwrale, Sourabh Selote, Abhijeet Shinde and Prof. Namrata Mahakalkar [10], proposed an artificial chatbot using NLP (Natural Language Processing) which can be done in two ways the first via written text and the second is via verbal or voice communication. Written communication is much easier than the verbal communication. This paper introduces an interest in some emerging capabilities for evolving speed understanding and processing in virtual human dialogue system [10].

\section{PROPOSED METHODOLOGY}

The proposed methodology makes use of both qualitative and quantitative perspectives, and includes a broad array of approaches such as literature reviews, expert opinions, focus groups, and content validation [14].

The proposed system will have the following modules:

A] Online Enquiry:

Students can enquire about facilities and query related to exams, academics, fee structure, etc.

Students can also ask questions related to placement activities. 


\section{B] Online Chatbot:}

The result can be showed in the form of images and card format or in text format. The query will be answered on the basis of questions asked and the language model built and also the response media created.

Users that want to enquire about the college at the time of admission or any competition held in the college can query to the chat-bot.

\section{Given below is the system architecture of this chat-bot:}

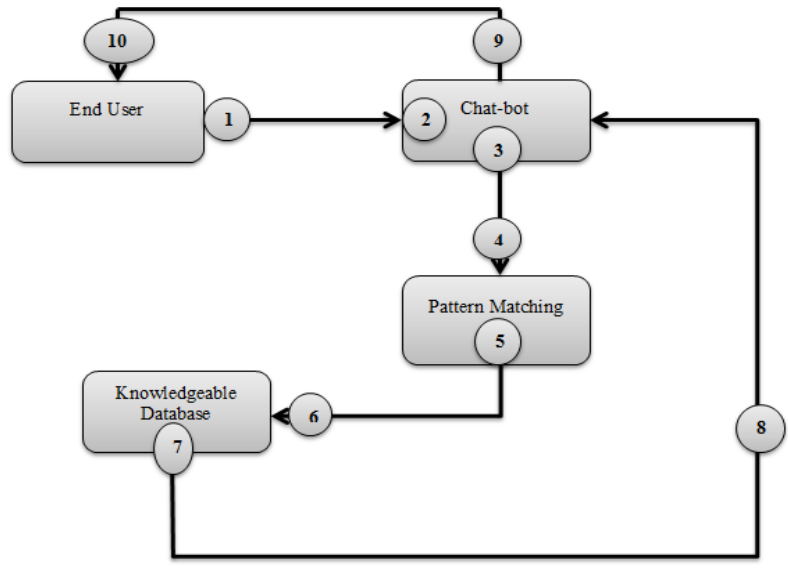

The basic algorithm that will be implemented for working of this proposed system is as follows:

Step 1: Start.

Step 2: Get the input query from the user.

Step 3: The query is pre-processed. E.g. suppose there is this query "what are the project domains for CSE fourth year major projects." So, we are going to remove these stop words like "are", "the" using pre-processing technique.

Step 4: Fetch the remaining keywords from the query.

Step 5: Match the fetched keywords with the keywords in Knowledge base, and provide an appropriate response.

Step 6: Further the Database module is used to call proper services using entity information to find proper data.

Step 7: The keywords will be matched with the help of keyword matching algorithm.

Step 8: It returns the query response to the bot.

Step 9: Chat-bot packages the data into proper response for display by the client.

\section{Step 10: Exit}

\section{CONCLUSION}

The goal of the system is to help the students to stay updated with their college activities. Artificial Intelligent is the fastest growing technology everywhere in the world, with the help of Artificial Intelligent and Knowledgeable database. We can make the transformation in the pattern matching and virtual assistance. This system is developing chat bot based on android system so with the combination of Artificial Intelligent Knowledgeable database and virtual assistance. We can develop such chat bot which will make a conversion between human and machine and will satisfy the question raised by user. The main motive of the project is to reduce the work load on the college's office staff and reduce the response time to a user's query.

\section{REFERENCES}

[1] Ms.Ch.Lavanya Susanna, R.Pratyusha, P.Swathi, P.Rishi Krishna, V.Sai Pradeep, "College Enquiry Chatbot", International Research Journal of Engineering and Technology (IRJET), e-ISSN: 2395 0056, p-ISSN: 2395-0072, Volume: 07 Issue: 3 Mar 2020 pp 784788 .

[2] Assistant Prof Ram Manoj Sharma, "Chatbot based College Information System”, RESEARCH REVIEW International Journal of Multidisciplinary, ISSN: 2455-3085 (Online), Volume-04, Issue03, March-2019, pp 109-112.

[3] P.Nikhila, G.Jyothi, K.Mounika, Mr. C Kishor Kumar Reddy and Dr. B V Ramana Murthy on , "Chatbots Using Artificial Intelligence", International Journal of Research and Development,Volume VIII, Issue I, January/2019, ISSN NO:22366124, pp 1-12.

[4] Payal Jain, "College Enquiry ChatBot Using Iterative Model", International Journal of Scientific Engineering and Research (IJSER),ISSN (Online): 2347-3878, Volume 7 Issue 1, January 2019, pp 80-83.

[5] Sagar Pawar, Omkar Rane, Ojas Wankhade, Pradnya Mehta, "A Web Based College Enquiry Chatbot with Results", International Journal of Innovative Research in Science, Engineering and Technology, ISSN(Online): 2319-8753, ISSN (Print): 2347-6710, Vol. 7, Issue 4, April 2018, pp 3874-3880.

[6] Harsh Pawar, Pranav Prabhu, Ajay Yadav, Vincent Mendonca Joyce Lemos, "College Enquiry Chatbot Using Knowledge in Database", International Journal for Research in Applied Science \& Engineering Technology (IJRASET), ISSN: 2321-9653; IC Value: 45.98, SJ Impact Factor: 6.887, Volume 6, Issue IV, April 2018, pp 2494- 2496.

[7] Jincy Susan Thomas, Seena Thomas, "Chatbot Using Gated End-toEnd Memory Networks", International Research Journal of Engineering and Technology (IRJET) e-ISSN: 2395-0056, p-ISSN: 2395-0072, Volume: 05 Issue: 03 Mar 2018, pp 3730- 3735.

[8] Prof. Suprita Das, Prof. Ela Kumar, "Determining Accuracy of Chatbot by applying Algorithm Design and Defined process", 4th International Conference on Computing Communication and Automation (ICCCA), 2018, 978-1-5386-6947-1/18/2018 IEEE, pp 1-6.

[9] Prof.K.Bala, Mukesh Kumar ,Sayali Hulawale, Sahil Pandita, "Chatbot For College Management System Using A.I", International Research Journal of Engineering and Technology (IRJET) e-ISSN: 2395-0056, p-ISSN: 2395-0072, Volume: 04 Issue: 11 | Nov -2017, pp 2030-2033.

[10] Nitesh Thakur, Akshay Hiwrale, Sourabh Selote, Abhijeet Shinde and Prof. Namrata Mahakalkar, "Artificially Intelligent Chatbot", Universal Research Reports, ISSN : 2348 - 5612, Volume : 04 , Issue : 06, July - September 2017, pp 43-47.

[11] Amey Tiwari, Rahul Talekar, Prof.S.M.Patil, "College Information Chat Bot System", International Journal of Engineering Research and General Science, ISSN 2091-2730, Volume 5, Issue 2, MarchApril, 2017, pp 131-137.

[12] Malusare Sonali Anil, Kolpe Monika Dilip, Bathe Pooja Prashant, "Online Chatting System for College Enquiry using Knowledgeable Database", Savitribai Phule Pune University, Preliminary Project Report, pp 1-53,2017.

[13] Balbir Singh Bani, Ajay Pratap Singh, "College Enquiry Chatbot Using A.L.I.C.E (Artificial Linguistic Internet Computer Entity)", International Journal of New Technology and Research (IJNTR), ISSN:2454-4116, Volume-3, Issue-1, January 2017 Pages 64-65. https://www.google.com/ 